\title{
A comparison of liquid-based cytology and Pap smear as a screening method for cervical cancer
}

\author{
JIE ZHU $^{1 *}$, INGRID NORMAN ${ }^{2 *}$, KRISTINA ELFGREN $^{1}$, VERA GABERI $^{1}$, \\ BJORN HAGMAR $^{3}$, ANDERS HJERPE ${ }^{2}$ and SONIA ANDERSSON ${ }^{1}$ \\ ${ }^{1}$ Department for Clinical Science, Intervention and Technology, Division of Obstetrics and Gynecology; \\ ${ }^{2}$ Laboratory of Clinical Pathology and Cytology, Department of Laboratory Medicine, Karolinska \\ University Hospital at Huddinge, Karolinska Institute, S-141 86 Stockholm, Sweden; \\ ${ }^{3}$ Institute of Pathology, The National University Hospital, 0027 Oslo, Norway
}

Received February 14, 2007; Accepted March 23, 2007

\begin{abstract}
The implementation of population-based screening for cervical cancer with Pap smear in the early sixties was set to detect and treat precancerous lesions, hopefully preventing a subsequent invasive cervical cancer. Epidemiological data indicate that organized screening has a major impact on morbidity and mortality from cervical cancer. The limited sensitivity of a single smear necessitates repeated smears in organized program. It is suggested that liquid-based cytology improves the sensitivity. The aim of this split-sample study was to compare ThinPrep liquid-based cytology with conventional Pap smear, relying on a laboratory with long-term experience of the latter. In total, 137 women with atypical Pap smear in population-based cervical screening were enrolled for the splitsample study. The performance of both techniques (ThinPrep liquid-based cytology and conventional Pap smear) were compared and validated by a histological follow-up. Women without representative histological biopsy were excluded from the study. Pap smear had sensitivity for detection of CIN2-3 of $47 \%$ compared to $66 \%$ for liquid-based material. The concordance of the two sampling techniques with the histological diagnosis was $37 \%$ and $53 \%$, respectively, this difference being statistically significant. The proportion of reports on atypical squamous cells of undetermined significance (ASCUS) was significantly less in the liquidbased material, $4.3 \%$ compared to $8 \%$ of the conventional smears. This improved sensitivity in combination with the
\end{abstract}

Correspondence to: Dr Sonia Andersson, Department for Clinical Science, Intervention and Technology, Division of Obstetrics and Gynecology, Karolinska University Hospital, Huddinge, Karolinska Institute, 14186 Stockholm, Sweden

E-mail: sonia.andersson@telia.com

${ }^{*}$ Contributed equally

Key words: screening, Pap smear, cervical intraepithelial neoplasia, liquid-based cytology, cervical cancer possibility to perform reflex testing such as HPV DNA or p16 immunocytochemistry without renewed sampling gives ThinPrep a substantial advantage and makes the liquid-based technique interesting.

\section{Introduction}

Only second to breast cancer, cervical carcinoma is the most common malignancy among women worldwide (1-3). Its high mortality makes cervical cancer an important public health problem. Epidemiological and molecular biological studies have shown that persistent infection with high-risk HPV is necessary in the pathogenesis of cervical cancer (4). At present, most cervical carcinomas are considered to harbour oncogenic types of HPV (5) type 16, 18, 45, 31 and 33 being the most frequently identified viruses in these lesions (6).

Early detection of cervical cellular changes and cervical intraepithelial neoplasia (CIN) followed by appropriate treatment will reduce the risk of developing cancer. This was first made possible in the early 1940s by the introduction of the Papanicolaou (Pap) smear. Since the early sixties, population-based screening with Pap smears has been used to detect precancerous lesions. Epidemiological data show that organized screening with Pap smear has had a major impact on both morbidity and mortality from cervical cancer. In Sweden, nearly one million cytology tests are performed annually, of which 3-4\% show some form of cellular atypia. Subsequently, this has lead to a reduction of $\sim 75 \%$ in the incidence of cervical carcinoma (7).

The technique is fairly simple and inexpensive; however, there is room for improvements in sensitivity which varies between $50-70 \%$. The high false-negative rate concerns several factors associated with both sampling and interpretation. Conventional Pap smears can sometimes be difficult to interpret due to uneven cell distribution overlapping cells, blood or inflammation.

Our aim was to compare conventional Pap smear to liquidbased cytology $\left(\right.$ ThinPrep ${ }^{\circledR}$ ) during follow-up screening among women with cytologic abnormalities found in the Swedish population-based, organized screening program for cervical cancer. To the best of our knowledge, no studies have been 
published documenting the use of liquid-based cytology in Sweden. The study was approved by the local ethics committee of Karolinska Hospital, Stockholm, Sweden.

\section{Materials and methods}

Patients. We consecutively enrolled 137 women with any grade of cytologic abnormalities detected at a populationbased cervical cancer screening program, their mean age being 35.5 years (median: 34 years; range: 18 to 60 years). The women were examined 2-6 months later with colposcopy at the Gynaecological Department at Karolinska University Hospital Huddinge, Stockholm. A Zeiss OMPI colposcope was used for magnification. The ectocervix and distal part of the endocervix were stained with 5\% acetic acid. Punch biopsies were obtained from acetowhite areas. When no acetowhite area was observed, a biopsy at 12 o'clock was taken close to the squamo-columnar junction.

The histological samples were evaluated by the local pathologist and classified according to the WHO (CIN classification). Based on the most severe grade of CIN found, 28 lesions were classified as CIN1, 43 as CIN2, and 34 as CIN3, while squamous cell carcinoma was found in two cases. In 30 women the biopsy failed to demonstrate any epithelial lesion. The sensitivity of the two cytological preparation techniques was evaluated with the histopathology as gold standard.

A split-sample study was designed for evaluation of the performance of the two cytological methods applied to paired specimens. A conventional Pap smear was first produced, and the remaining material on the spatula and in the brush was rinsed off in the liquid medium. The material taken for the ThinPrep ${ }^{\circledR}$ procedure was always the remains from the Pap smear preparation. The liquid-based material was prepared, using the ThinPrep 2000 Processor (Cytyc Corporation, Boxborough, MA, USA) (8). Different cytotechnologists evaluated the two cytological tests independently, the evaluation of the ThinPrep material being performed after practice with this particular material.

Statistical analysis. Chi-square statistics were calculated to test the significance of the data with evident ordering. All statistical tests were two-sided and the null hypothesis of no difference was rejected at a significance level of $\alpha=0.05$. Logistic regression was used to assess the significance of the differences in paired data, for instance, comparison of the sensitivity of cytology Pap smear and ThinPrep testing in the same subjects.

\section{Results}

The results from the second ordinary Pap smear from the 137 enrolled women showed atypical squamous cells of undetermined significance (ASCUS) in 11 cases (8\%), low grade squamous intraepithelial lesions (LSIL) in 40 cases (29\%), more advanced lesions (high grade squamous intraepithelial lesions; HSIL, undetermined high grade lesion; ASC-H, or malignant cells) in 56 cases (41\%). Two cases were reported as atypical glandular lesions (AGUS) while 28 (20\%) were considered within normal limits (Fig. 1). With the parallel

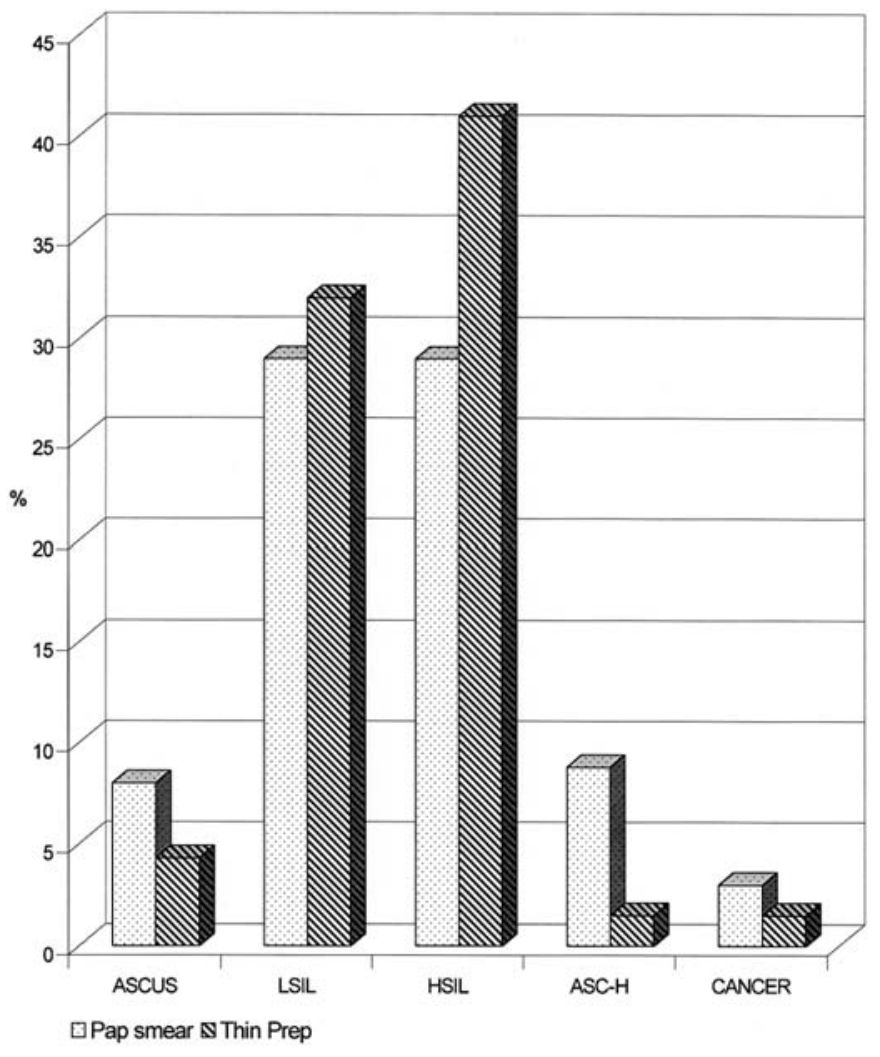

Figure 1. Cytological diagnoses obtained from split-samples prepared with conventional Papanicolaou technique and with ThinPrep. The smears were taken during the follow-up of abnormal findings in the organized screening program. The changed rates of ASCUS, ASC-H and HSIL are statistically significant when comparing the two preparation techniques.

liquid-based material, ASCUS was reported significantly less often (6 cases, $4 \%$ ), LSIL was found in 44 cases (32\%), while 57 cases $(42 \%)$ had a more advanced lesion. AGUS was found in 2 cases, while 25 cases $(18 \%)$ were considered within normal limits. Cases of CIN2 ${ }^{+}$found from the liquid-based material were considerably more often diagnosed as HSIL, along with less common use of ASC-H.

The results of repeat Pap smears, histology of colposcopically directed biopsies and ThinPrep testing are summarized in Tables I and II. Among the 28 women with a normal second Pap smear, the simultaneous biopsy showed a CIN2+ lesion in 12 cases (43\%). Of the 109 women with an atypical second Pap smear, $65(60 \%)$ had a CIN2+ lesion and in 2 cases the histology showed invasive cervical cancer. The 'false positive rate' of cytology from 109 women with an atypical second Pap smear was 23\% (25/109) (Table I).

Of the 25 women with a normal ThinPrep test, $9(36 \%)$ had a CIN2+ lesion and among 112 women with an abnormal ThinPrep test, $68(61 \%)$ had a CIN2+, while in 23 cases $(20 \%)$ the biopsy was normal. These results were similar to those obtained by Pap smear (Table II).

In three women where the second Pap smear was classified as ASCUS the histology showed CIN2+. The sensitivity for detecting a CIN2+ lesion with Pap smear was $47 \%$ (C.I ${ }_{0.95}$ : $36-58 \%$ ), compared with $66 \%$ (C.I. $_{0.95}: 55-76 \%$ ) for ThinPrep testing. The concordance with histopathology was $37 \%$ for 
Table I. Results of the histological analysis of biopsies in Pap smear-negative and Pap smear-positive women.

\begin{tabular}{lccccr}
\hline & CIN1 & CIN2 $^{+}$ & CA & WNL & Total \\
\hline CPAP Normal & 11 & 12 & 0 & 5 & 28 \\
CPAP Pathologic & 17 & 65 & 2 & 25 & 109 \\
Total & 28 & 77 & 2 & 30 & 137 \\
\hline
\end{tabular}

CPAP, conventional Papanicolaou test.

Table II. Results of the histological analysis of biopsies in ThinPrep-negative and ThinPrep-positive women.

\begin{tabular}{lrrcrr}
\hline & CIN1 & CIN2 $^{+}$ & CA & WNL & Total \\
\hline TPPT Normal & 9 & 9 & 0 & 7 & 25 \\
TPPT Pathologic & 19 & 68 & 2 & 23 & 112 \\
Total & 28 & 77 & 2 & 30 & 137 \\
\hline
\end{tabular}

TPPT, ThinPrep Pap test.

Pap smear, while the corresponding rate for ThinPrep was $53 \%$; this difference being statistically significant already with the present limited material $(\mathrm{p}=0.011)$.

\section{Discussion}

During the last decades in Sweden, a combination of organized and opportunistic screening has achieved a substantial reduction in the incidence of squamous carcinoma $(9,10)$. However, Pap smear has a high false-negative rate $(11,12)$. A review of evidence-based data revealed that as many as $50 \%$ of precancerous cervical lesions may be missed with a single Pap test (13).

In addition, the abnormal report rate is important for a successful health control screening; high rates of referral and samples without definite diagnosis such as ASCUS will greatly increase the cost of the program. However, patients who develop invasive cervical carcinoma in spite of their participation in the screening program repeatedly show milder lesions (LSIL or ASCUS) in these preceding smears; this demonstrates the importance of cytological stringency. Liquidbased cytology, such as the ThinPrep ${ }^{\circledR}$ technique, makes immediate fixation easier and leaves the cells better visualized.

The ThinPrep test was approved by the Food and Drug Administration (FDA) 1996 based on split-sample analysis (14). The rates of squamous intraepithelial lesions (SIL), low-grade as well as high-grade, and glandular lesions both increased with ThinPrep test, as has been demonstrated by numerous studies (15-19). However, some studies do not support the implementation of LBC at present and further studies are recommended in order to evaluate the place of this technology in the clinic $(20,21)$. The sensitivity for detection of invasive cancer was similar for the two sampling techniques (22). In a systematic review by Davey et al, 56 primary studies were reviewed. The authors did not find liquid-based cytology to be more accurate than conventional cytology, equivalent performance might be sufficient if liquid-based cytology has other advantages, such as the opportunity for HPV DNA testing (23). Obwegeser and Schneider in the comments to the editor wrote that the new technology will not be the answer to the remaining incidence and mortality rates of cervical cancer. The increasing coverage rate has been shown to be the key to success (24).

In our study, the sensitivity for detecting a high-grade lesion was somewhat better with the ThinPrep sample (66\%) compared to conventional Pap smear (47\%), although the difference is not significant at the chosen level of significance. This is consistent with the findings by Bernstein et al in their meta-analysis (17). The concordance of Pap smear and ThinPrep with histopathology was $37.2 \%$ and $53.3 \%$, respectively, a statistically significant difference.

The liquid-based material not only gave a slightly better sensitivity; it more often allowed a definite diagnosis of high-grade lesions, a decreased rate of ASC-H, and a better concordance with the simultaneous histopathological examination. Furthermore, it was possible to obtain higher sensitivity together with significantly reduced ASCUS, 8\% with Pap smear to $4 \%$ with liquid-based material. The possibility for better diagnostic stringency may correlate with both better specimen adequacy and improved cell morphology, similar to previous studies $(22,25-29)$. The occurrence of false-negative reports not only correlates with the morphological quality, but also involves other factors; such as whether the abnormal cells really are present in the sample in a recognizable form, that is, factors merely related to sampling and pre-laboratory handling. In this respect, the two methods fared equally. The ThinPrep technique allows an immediate fixation after sampling, which not only should eliminate problems with too thick a smear but also drying artefacts and other concerns. It should be emphasized that the present results with ThinPrep were obtained using the remains from preparations of conventional Pap smears.

All abnormal samples are associated with expensive follow-up investigations. It is under debate whether HPV testing may improve an organized cytological screening program, particularly as a second line test to distinguish precancerous lesions of the milder abnormalities (ASCUS and LSIL) from lesions that are reactive or degenerated. Such triage is costly; to a large extent the cost of recall and resampling. An additional advantage with the liquid-based technique would be that such second line analysis for HPV DNA, HPV integration, p16 or any other predictive marker, could be performed directly with the remaining sample material available in the laboratory without the need to recall the patient. Although in the future, vaccination might prevent a significant part of cervical cancers worldwide, the need for screening in some form is likely to remain.

The ThinPrep procedure increases the laboratory costs due to disposables; these costs must be covered within the screening program. Hoelund et al concluded that liquid-based cytology did not increase the total cost for the cervical screening system in Odense, Denmark (30). Although the ThinPrep preparation procedure improved the performance of 
vaginal cytology in the present split-sample study, its utility in organized screening must be evaluated in such a setting. If the sensitivity is sufficiently improved, this may allow for extended sampling intervals without decreasing the total sensitivity of the program. Furthermore, if second line analysis would be included when following up abnormalities, then this will also favourably influence the economy. All these factors must be carefully evaluated, before liquid-based cytology can be recommended as a routine method in the screening program. Such studies have already been initiated.

\section{Acknowledgements}

We would like to express our appreciation to Bo Nilsson for the statistical analysis. This study was supported by the Swedish Cancer Funds and the funds of the Karolinska Institute.

\section{References}

1. Klinkhamer PJ, Meerding WJ, Rosier PF and Hanselaar AG: Liquid-based cervical cytology. Cancer 99: 263-267, 2003.

2. Parkin DM, Pisani P and Ferlay J: Estimates of the worldwide incidence of 25 major cancers in 1990. Int J Cancer 80: 827-841, 1999.

3. Parkin DM, Bray F, Ferlay J and Pisani P: Estimating the world cancer burden: Globocan 2000. Int J Cancer 94: 153-156, 2001.

4. Bosch FX, Manos MM, Munoz N, Sherman M, Jansen AM, Peto J, et al: Prevalence of human papillomavirus in cervical cancer: a worldwide perspective. International biological study on cervical cancer (IBSCC) Study Group. J Natl Cancer Inst 87: 796-802, 1995.

5. Walboomers JM, Jacobs MV, Manos MM, Bosch FX, Kummer JA, Shah KV, et al: Human papillomavirus is a necessary cause of invasive cervical cancer worldwide. J Pathol 189: 12-19, 1999.

6. Munoz N, Bosch FX, de Sanjose S, Herrero R, Castellsague X, Shah KV, et al: Epidemiologic classification of human papillomavirus types associated with cervical cancer. N Engl J Med 348: 518-527, 2003.

7. Bergstrom R, Sparen P and Adami HO: Trends in cancer of the cervix uteri in Sweden following cytological screening. Br J Cancer 81: 159-166, 1999.

8. Linder $\mathrm{J}$ and Zahniser D: ThinPrep Papanicolaou testing to reduce false-negative cervical cytology. Arch Pathol Lab Med 122: 139-144, 1998.

9. Mahlck CG, Jonsson H and Lenner P: Pap smear screening and changes in cervical cancer mortality in Sweden. Int J Gynaecol Obstet 44: 267-272, 1994.

10. Ponten J, Adami HO, Friberg LG, Gustafsson L, Miller AB, Parkin M, et al: HPV and cervical cancer. Int J Cancer 63: 317, 1995.

11. Macgregor JE, Campbell MK, Mann EM and Swanson KY: Screening for cervical intraepithelial neoplasia in north east Scotland shows fall in incidence and mortality from invasive cancer with concomitant rise in preinvasive disease. BMJ 308: 1407-1411, 1994.

12. Kinney WK, Manos MM, Hurley LB and Ransley JE: Where's the high-grade cervical neoplasia? The importance of minimally abnormal Papanicolaou diagnoses. Obstet Gynecol 91: 973-976, 1998.

13. Sherman ME, Mango LJ, Kelly D, Paull G, Ludin V, Copeland C, et al: PAPNET analysis of reportedly negative smears preceding the diagnosis of a high-grade squamous intraepithelial lesion or carcinoma. Mod Pathol 7: 578-581, 1994.
14. Limaye A, Connor AJ, Huang $X$ and Luff R: Comparative analysis of conventional Papanicolaou tests and a fluid-based thin-layer method. Arch Pathol Lab Med 127: 200-204, 2003.

15. Bentz JS: Liquid-based cytology for cervical cancer screening. Expert Rev Mol Diagn 5: 857-871, 2005.

16. Hussein T, Desai M, Tomlinson A and Kitchener HC: The comparative diagnostic accuracy of conventional and liquidbased cytology in a colposcopic setting. Br J Obstet Gynaecol 112: 1542-1546, 2005.

17. Bernstein SJ, Sanchez-Ramos L and Ndubisi B: Liquid-based cervical cytologic smear study and conventional Papanicolaou smears: a meta-analysis of prospective studies comparing cytologic diagnosis and sample adequacy. Am J Obstet Gynecol 185: 308-317, 2001.

18. Sherman ME, Mendoza M, Lee KR, Ashfaq R, Birdsong GG, Corkill ME, et al: Performance of liquid-based, thin-layer cervical cytology: correlation with reference diagnoses and human papillomavirus testing. Mod Pathol 11: 837-843, 1998.

19. Austin RM and Ramzy I: Increased detection of epithelial cell abnormalities by liquid-based gynecologic cytology preparations. A review of accumulated data. Acta Cytol 42: 178-184, 1998.

20. Confortini M, Bulgaresi P, Cariaggi MP, Carozzi FM, Cecchini S, Cipparrone I, Maddau C, Rossi R, Troni GM, Zappa M and Ciatto S: Conventional pap smear and liquid-based cervical cytology smear: comparison from the same patient. Tumori 88: 288-290, 2002.

21. Moseley RP and Paget S: Liquid-based cytology: is this the way forward for cervical screening? Cytopathology 13: 71-82, 2002.

22. Chacho MS, Mattie ME and Schwartz PE: Cytohistologic correlation rates between conventional Papanicolaou smears and ThinPrep cervical cytology: a comparison. Cancer 99: 135-140, 2003.

23. Davey E, Barratt A, Irwing L, Chan SF, Macaskill P, Mannes P and Saville AM: Effect of study design and quality on unsatisfactory rates, cytology classifications, and accuracy in liquid-based versus conventional cervical cytology: a systematic review. Lancet 367: 122-132, 2006.

24. Obwegeser J and Schneider V: Thin-layer cervical cytology: a new meta-analysis. Lancet 367: 88-89, 2006.

25. Negri G, Menia E, Egarter-Vigl E, Vittadello F and Mian C: ThinPrep versus conventional Papanicolaou smear in the cytologic follow-up of women with equivocal cervical smears. Cancer 99: 342-345, 2003.

26. Guo M, Hu L, Martin L, Liu S, Baliga M and Hughson MD: Accuracy of liquid-based Pap tests: comparison of concurrent liquid-based tests and cervical biopsies on 782 women with previously abnormal Pap smears. Acta Cytol 49: 132-138, 2005.

27. Monsonego J, Autillo-Touati A, Bergeron C, Dachez R, Liaras J, Saurel $\mathrm{J}$, et al: Liquid phase cytology in the primary screening for cervical cancer: a multicenter study. Gynecol Obstet Fertil 29: 799-807, 2001.

28. Luthra UK, Chishti M, Dey P, Jolly SV, Abdulla M, Das DK, et al: Performance of monolayered cervical smears in a gynecology outpatient setting in Kuwait. Acta Cytol 46: 303-310, 2002.

29. Park IA, Lee SN, Chae SW, Park KH, Kim JW and Lee HP: Comparing the accuracy of ThinPrep Pap tests and conventional Papanicolaou smears on the basis of the histologic diagnosis: a clinical study of women with cervical abnormalities. Acta Cytol 45: 525-531, 2001.

30. Hoelund B: Implementation of liquid-based cytology in the screening programme against cervical cancer in the County of Funen, Denmark, and status for the first year. Cytopathology 14: 269-274, 2003. 